\title{
Rivaroxaban and Acetylsalicylic Acid for Prevention of Venous Thromboembolism Following Total Knee Arthroplasty in Korean Patients
}

\author{
Kyu Sung Chung, $\mathrm{MD}^{1}$, Tae Yang Shin, $\mathrm{MD}^{2}$, Sang Hoon Park, $\mathrm{MD}^{3}$, Hyuck Kim, $\mathrm{MD}^{4}$, and \\ Choong Hyeok Choi, $\mathrm{MD}^{3}$ \\ ${ }^{1}$ Department of Orthopedic Surgery and Sports Medical Center and Sports Medical Research Institute, Seoul Paik Hospital, College of Medicine, Inje University, \\ Seoul; ${ }^{2}$ Department of Orthopaedic Surgery, Jeonju Korea Hospital, Jeonju; ${ }^{3}$ Department of Orthopaedic Surgery, College of Medicine, Hanyang University, Seoul; \\ ${ }^{4}$ Department of Thoracic and Cardiovascular Surgery, College of Medicine, Hanyang University, Seoul, Korea
}

\begin{abstract}
Purpose: To investigate the incidence of venous thromboembolism (VTE) after total knee arthroplasty (TKA) with chemoprophylaxis using acetylsalicylic acid (AA) or rivaroxaban in Korean patients.

Materials and Methods: Between May 2011 and November 2013, 268 TKA patients (330 cases) were randomly allocated to 3 groups (group A: subcutaneous injection of 5,000 IU low-molecular-weight heparin for 2 days followed by oral administration of 100 mg AA for 5 days; group X7: oral administration of 10mg rivaroxaban for 7 days; and group X10: oral administration of $10 \mathrm{mg}$ rivaroxaban for 10 days). Multidetector-row computed tomography (MDCT) was performed at 10 days and 3 months postoperatively to evaluate VTE changes.

Results: The VTE incidence was $38.2 \%, 20.0 \%$, and $10.0 \%$ in groups A, X7, and X10, respectively (p<0.001). Pulmonary embolism (PE) was identified in $19.1 \%, 10.0 \%$, and $2.7 \%$ in groups A, X7, and X10, respectively $(\mathrm{p}<0.001)$. Proximal or symptomatic deep vein thrombosis $(\mathrm{DVT})$ occurred primarily in group A, but the incidence was not significantly different among groups. On follow-up MDCT, PE was resolved completely with treatment in 29/30 (96.7\%), and so was asymptomatic distal DVT in 24/27 (88.8\%) without treatment.

Conclusions: Rivaroxaban had a lower incidence of overall VTE than AA, but no difference was observed in symptomatic VTE. The 10-day course of rivaroxaban had a lower incidence of overall VTE than the 7-day course.
\end{abstract}

Keywords: Knee, Arthroplasty, Venous thromboembolism, Rivaroxaban, Acetylsalicylic acid

\section{Introduction}

Since total knee arthroplasty (TKA) is considered a high risk factor for venous thromboembolism (VTE), thromboprophylaxis is commonly recommended ${ }^{1)}$. However, the actual incidence of

Received November 24, 2017; Revised February 11, 2018;

Accepted March 29, 2018

Correspondence to: Choong Hyeok Choi, MD

Department of Orthopaedic Surgery, College of Medicine, Hanyang University, 222 Wangsimni-ro, Seongdong-gu, Seoul 04763, Korea

Tel: +82-2-2290-8483, Fax: +82-2-2299-3774

E-mail: chhchoi@hanyang.ac.kr

This is an Open Access article distributed under the terms of the Creative Commons Attribution Non-Commercial License (http://creativecommons.org/licenses/by-nc/4.0/) which permits unrestricted non-commercial use, distribution, and reproduction in any medium, provided the original work is properly cited.
VTE and the need for routine thromboprophylaxis after TKA in Asians are controversial. A recent meta-analysis showed that the incidences of deep vein thrombosis (DVT) and symptomatic pulmonary embolism (PE) were low ( $40.4 \%$ and $0.01 \%$, respectively) in Asians without chemoprophylaxis, despite the westernized lifestyle and aging of the population ${ }^{2}$. However, since the incidence of DVT proven by venography is reported to be $50 \%-76.5 \%$ and that of PE proven by lung perfusion scan is $17.1 \%$ in cases without prophylaxis, routine thromboprophylaxis should be reconsidered $^{3,4)}$. In contrast to Western studies, which typically describe the incidence of VTE with chemoprophylaxis, most Asian reports have investigated the incidence without chemoprophylaxis. Thus, due to insufficient data, the need for prophylaxis after TKA in Asians remains debatable.

Recently, rivaroxaban (factor Xa inhibitor) has shown superior 
results compared with low-molecular-weight heparin (LMWH) $)^{5)}$. However, there has been no report on the VTE incidence after TKA with chemoprophylaxis using rivaroxaban or acetylsalicylic acid (AA) in Asian patients. Traditionally, the VTE prevalence is believed to be lower in Asians than in Caucasians ${ }^{6}$, and recent reports confirmed this belief ${ }^{2}$, and shorter prophylactic regimens tend to be favored in Asian patients; however, no supporting evidence has been found thus far.

In the present study, we investigated the actual incidence of VTE and hemorrhagic outcome after TKA with currently available chemical thromboprophylaxis in Korean individuals. We also studied whether a shorter prophylactic duration has a similar prophylactic effect compared with the currently recommended duration in Korean patients.

\section{Materials and Methods}

The protocol was approved by the Institutional Review Board (HYUH IRB no. 2011-R-37), and all patients provided informed consent. The inclusion criteria for this prospective, randomized and controlled study were patients who underwent primary TKA, including unilateral or staged bilateral TKA with a 2-week interval, between May 2011 and November 2013. A total of 278 patients (341 cases) who met the inclusion criteria were allocated into 3 groups according to the different prophylactic regimens. We assessed the patients for VTE using a 64-channel multidetector-row computed tomography (MDCT) indirect venography system (Brilliance 64; Philips, Eindhoven, The Netherlands) at 10 days postoperatively. The exclusion criteria included renal insufficiency, contrast allergy, simultaneous bilateral TKA, MDCT conducted before 10 days postoperatively due to suspicious VTE symptoms ${ }^{7,8)}$, a previous VTE history and varicose veins. After

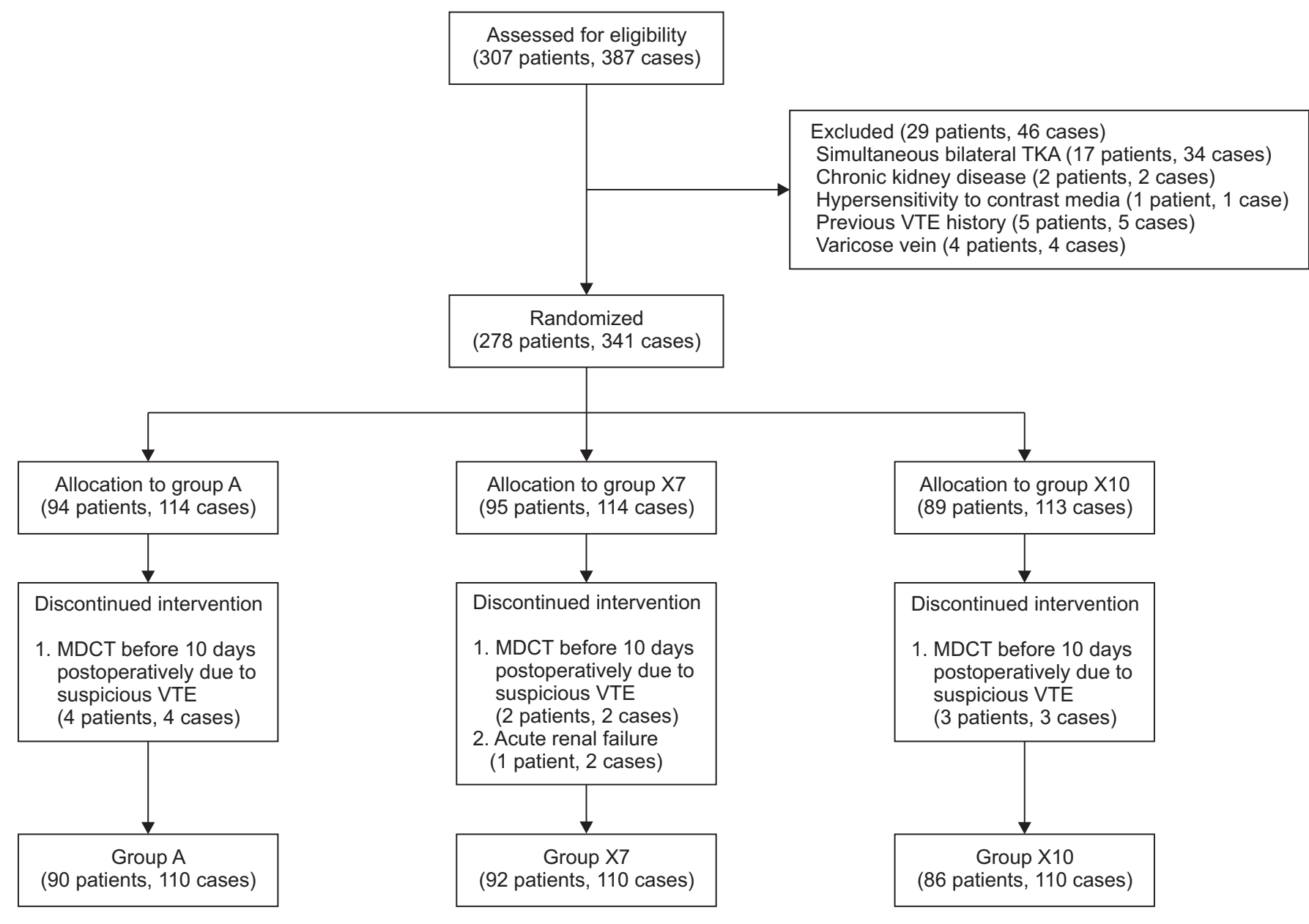

Fig. 1. Flow diagram of patients included in the present study. TKA: total knee arthroplasty, VTE: venous thromboembolism, MDCT: multidetectorrow computed tomography. 
applying the exclusion criteria, 268 patients were ultimately included in the study with 110 cases allocated in each group according to the computer-generated randomization code (Fig. 1). In the cases of staged bilateral TKA, the same prophylactic regimen was used for the first and second operations. Baseline demographics and clinical characteristics including Charlson comorbidity index were similar among 3 groups (Table 1).

\section{Thromboprophylactic Regimens}

Patients were randomly allocated into 3 groups according to the different prophylactic regimens. In group A (90 patients, 110 cases), subcutaneous injection of 5,000 international units (IU) of
Fragmin (dalteparin, LMWH; Pfizer, New York, USA) was given daily for 2 postoperative days, which was followed by 5 days of $100 \mathrm{mg}$ aspirin (AA; Bayer, Leverkusen, Germany) therapy. In group X7 (92 patients, 110 cases), a shorter regimen of $10 \mathrm{mg}$ Xarelto (rivaroxaban, factor Xa-inhibitor, Bayer) was given orally for 7 days postoperatively. In group X10 (86 patients, 110 cases), $10 \mathrm{mg}$ Xarelto was given orally for 10 days postoperatively. Prophylaxis was started at 6 hours after the end of surgery. For all patients, intermittent pneumatic compression was applied immediately after surgery and maintained for 7 days. However, a compression stocking was not applied. A continuous passive motion machine was used at 1 day postoperatively.

Table 1. Baseline Demographics and Clinical Characteristics

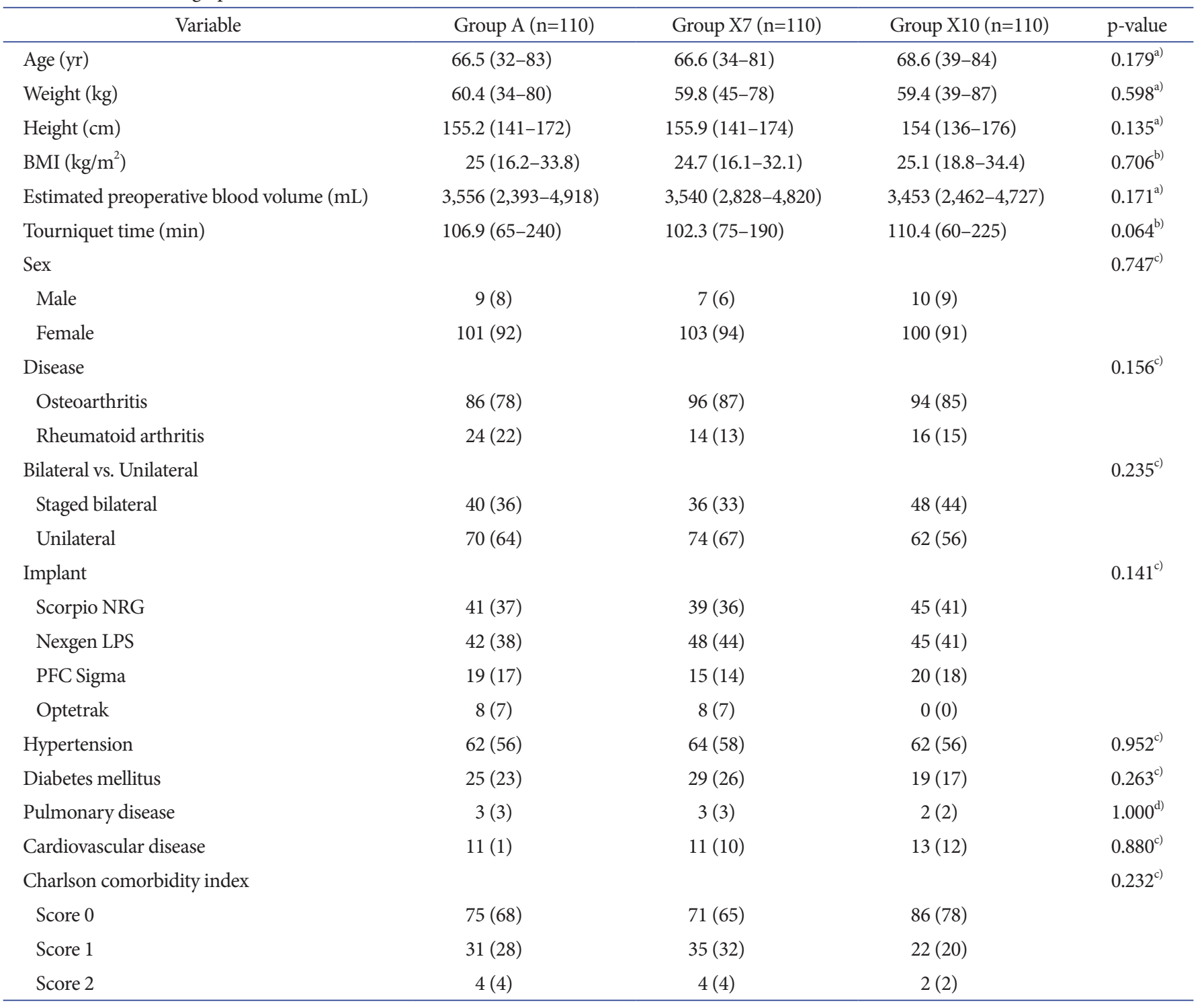

Values are presented as mean (range) or number of cases (\%).

${ }^{\text {a) }}$ Kruskal-Wallis test. ${ }^{\text {b) }}$ One-way analysis of variance test. ${ }^{\text {c) }}$ Chi-square test. ${ }^{\text {d) }}$ Fisher exact test. 


\section{Evaluation of VTE}

We assessed the occurrence of a VTE event using MDCT at 10 days postoperatively. Six seconds after the signal density level reached 100 hounsfield units (HU), a computed tomography (CT) scan was performed from the costophrenic angle to the lung apex. After the injection of contrast media (Ultravist 370, Iopromide, Bayer) thorough the antecubital vein, indirect venography was performed to obtain contrast-enhanced venous phase images. Based on the literature, the estimated radiation dose received per MDCT scan of this study is approximately 7 $\mathrm{mSv}$ for PE scan and $8 \mathrm{mSv}$ for DVT scan ${ }^{9,10}$. A single radiologist evaluated the CT images in a blinded manner. Symptomatic PE was defined as PE with additional symptoms, such as dyspnea, pleuritic chest pain, cough, hemoptysis, tachypnea, rales, or tachycardia ${ }^{7}$. Symptomatic DVT was defined as DVT involving discomfort of the calf or thigh, a Homan's sign, swelling, localized hotness, skin discoloration, tenderness, or prominence of the superficial veins ${ }^{8}$. If the patient presented with severe symptoms, we performed MDCT before 10 days postoperatively. The VTE cases were divided into PE and DVT, and the latter was further subcategorized into proximal DVT (occurring in the popliteal vein and above) and distal DVT (occurring below the popliteal vein).

If a patient had asymptomatic distal DVT, the patient was only observed conservatively without any treatment. We only treated patients with PE, symptomatic DVT, or proximal DVT, and a pulmonologist or a chest surgeon was consulted for the management of these patients with anticoagulants. At 3 months postoperatively, patients who had VTE events underwent follow-up MDCT to evaluate the change in VTE.

\section{Evaluation of Hemorrhagic Outcome}

The bleeding amount was checked by drain removed routinely after 48 hours. Bleeding events were classified as major or minor. Major bleeding comprised intracranial, intraocular, retroperitoneal, intraspinal or pericardial bleeding ${ }^{11)}$. Minor bleeding included any unexpected hematoma $\left(>25 \mathrm{~cm}^{2}\right)$, threatened wound hematoma, nasal, gingival, rectal or vaginal bleeding, macroscopic hematuria, coughing or vomiting blood ${ }^{12)}$. Transfusion volume was compared among groups. Additionally, the transfusion volume of staged bilateral TKA patients was compared to that of unilateral TKA patients in each group.

\section{Statistical Analysis}

The sample size and power calculation was based on the expected incidence of VTE that was approximately $50 \%{ }^{13)}$ in group
A, $20 \%{ }^{14)}$ in group X7, and $7 \%{ }^{12)}$ in group X10. The minimal expected difference in VTE incidence was noted between groups $\mathrm{X} 7$ and X10, which was $13 \%$. Statistical significance was set at 5\% $(\mathrm{p}<0.05)$ with a power of $80 \%$; thus, the minimum sample size for each group was set as 110 cases by the chi-square test, considering a drop-out rate of $10 \%$. Statistical analysis was performed with SPSS ver. 18.0 (SPSS Inc., Chicago, IL, USA). For comparison of the categorical and proportional variables, the Chi-square test was used. If more than $20 \%$ of the expected frequencies were less than 5 , the Fisher exact test was performed. One-way analysis of variance was used to compare the results of numerical continuous variables. However, for some variables without normal distribution, the Kruskal-Wallis test was used.

\section{Results}

The incidence of VTE is described in Table 2. Compared to group $\mathrm{A}$, the incidence was significantly lower in groups $\mathrm{X} 7$ and $\mathrm{X} 10$. The incidence was significantly lower in group X10 than that in group X7 ( $\mathrm{p}=0.038$ ). Group X10 had a significantly lower incidence compared with groups A and X7 in terms of PE and PE plus proximal DVT plus symptomatic DVT. In contrast, no significant differences were observed between groups $\mathrm{A}$ and $\mathrm{X} 7$ ( $p=0.056$ and $p=0.074$, respectively). The incidences of proximal DVT and symptomatic DVT were similar among the 3 groups, and symptomatic PE was not observed in any of the groups. All DVT events occurred on the operated side.

The results of follow-up MDCT are summarized in Table 3. In the cases of asymptomatic distal DVT only, 24/27 (88.8\%) demonstrated complete resolution, whereas the remaining 3 cases showed a reduced amount of thrombosis without symptoms. All the proximal and symptomatic DVT cases resolved completely, except for 4 patients who refused to take follow-up MDCT without suspicious VTE symptoms. In cases of PE, 96.7\% showed complete resolution (29/30); only 1 patient, in group X7, did not show resolution of $\mathrm{PE}$, which then progressed to chronic $\mathrm{PE}$. However, complete resolution of this patient's PE was confirmed by follow-up MDCT after 6 months of anticoagulation therapy.

The mean bleeding amount was similar among the 3 groups (692 $\mathrm{mL}$ in group $\mathrm{A}, 705 \mathrm{~mL}$ in group $\mathrm{X} 7$, and $700 \mathrm{~mL}$ in group $\mathrm{X} 10 ; \mathrm{p}=0.889$ ) and there was no observable major or minor bleeding event. The transfusion volume was similar among 3 groups (908 mL in group A, 1,014 mL in group X7, and 1,062 $\mathrm{mL}$ in group X10; $\mathrm{p}=0.072)$. The transfusion volume of staged bilateral TKA patients $(909 \mathrm{~mL}$ in group $\mathrm{A}, 1,011 \mathrm{~mL}$ in group $\mathrm{X} 7$, and $1,067 \mathrm{~mL}$ in group X10) was similar to that of unilateral 
Table 2. Incidence of Venous Thromboembolism (VTE) according to Different Chemical Prophylaxis Regimens

\begin{tabular}{|c|c|c|c|c|c|c|c|c|}
\hline \multirow{2}{*}{ Variable } & \multirow{2}{*}{$\begin{array}{l}\text { No. of } \\
\text { cases }\end{array}$} & \multicolumn{3}{|c|}{ Each group } & \multirow{2}{*}{ p-value ${ }^{a)}$} & \multicolumn{3}{|c|}{ p-value ${ }^{a)}$} \\
\hline & & A & $\mathrm{X} 7$ & $\mathrm{X} 10$ & & A vs. X7 & A vs. X10 & $\mathrm{X} 7$ vs. $\mathrm{X} 10$ \\
\hline No VTE & 255 & $68(71.8)$ & $88(80.0)$ & $99(90.0)$ & & & & \\
\hline VTE & 75 & $42(38.2)$ & $22(20.0)$ & $11(10.0)$ & $<0.001$ & 0.003 & $<0.001$ & 0.038 \\
\hline \multicolumn{9}{|l|}{ DVT only } \\
\hline Proximal only & 2 & $2(1.8)$ & $0(0)$ & $0(0)$ & $0.331^{\mathrm{b})}$ & $0.498^{\mathrm{b})}$ & $0.498^{\mathrm{b})}$ & - \\
\hline Distal only & 38 & $19(17.3)$ & $11(10.0)$ & $8(7.3)$ & 0.056 & 0.116 & 0.024 & 0.471 \\
\hline Proximal \& distal & 0 & $0(0)$ & $0(0)$ & $0(0)$ & - & - & - & - \\
\hline \multicolumn{9}{|l|}{ PE only } \\
\hline Asymptomatic & 11 & $3(2.7)$ & $5(4.5)$ & $3(2.7)$ & $0.798^{\mathrm{b})}$ & $0.721^{\mathrm{b})}$ & $1.000^{\mathrm{b})}$ & $0.721^{\mathrm{b})}$ \\
\hline Symptomatic & 0 & $0(0)$ & $0(0)$ & $0(0)$ & - & - & - & - \\
\hline DVT combined PE & 24 & $18(16.4)$ & $6(5.5)$ & $0(0)$ & $<0.001$ & 0.009 & $<0.001$ & $0.029^{\mathrm{b})}$ \\
\hline Proximal DVT only & 3 & $3(2.7)$ & $0(0)$ & $0(0)$ & $0.109^{\mathrm{b})}$ & $0.247^{\mathrm{b})}$ & $0.247^{\mathrm{b})}$ & - \\
\hline Distal DVT only & 20 & $15(13.6)$ & $5(4.5)$ & $0(0)$ & $<0.001$ & 0.019 & $<0.001$ & $0.060^{\mathrm{b})}$ \\
\hline Proximal \& distal DVT & 1 & $0(0)$ & $1(0.9)$ & $0(0)$ & $1.000^{\mathrm{b})}$ & $1.000^{\mathrm{b})}$ & - & $1.000^{\mathrm{b})}$ \\
\hline Any DVT & 64 & $39(35.5)$ & $17(15.5)$ & $8(7.3)$ & $<0.001$ & 0.001 & $<0.001$ & 0.056 \\
\hline Any PE & 35 & $21(19.1)$ & $11(10.0)$ & $3(2.7)$ & $<0.001$ & 0.056 & $<0.001$ & 0.027 \\
\hline Any proximal DVT & 6 & $5(4.5)$ & $1(0.9)$ & $0(0)$ & $0.051^{\mathrm{b})}$ & $0.212^{\mathrm{b})}$ & $0.060^{\mathrm{b})}$ & $1.000^{\mathrm{b})}$ \\
\hline Symptomatic DVT & 8 & $5(4.5)$ & $3(2.7)$ & $0(0)$ & $0.105^{\mathrm{b})}$ & $0.721^{\mathrm{b})}$ & $0.060^{\mathrm{b})}$ & $0.247^{\mathrm{b})}$ \\
\hline $\begin{array}{l}\text { PE+symptomatic DVT } \\
\text { +proximal DVT }\end{array}$ & 41 & $24(21.8)$ & $14(12.7)$ & $3(2.7)$ & $<0.001$ & 0.074 & $<0.001$ & 0.005 \\
\hline
\end{tabular}

Values are presented as number (\%).

DVT: deep vein thrombosis, PE: pulmonary embolism.

${ }^{\text {a) }}$ Chi-square test. ${ }^{\text {b) }}$ Fisher exact test.

Table 3. Prognosis of Venous Thromboembolism by Multidetector-Row Computed Tomography (MDCT) at 3-Month Follow-Up

\begin{tabular}{|c|c|c|}
\hline Variable & All groups $(n=330)$ & $\begin{array}{l}\text { Postoperative 3-month MDCT follow-up results } \\
\text { (resolved cases/MDCT follow-up cases) }\end{array}$ \\
\hline DVT only & $40(12.1)$ & Total resolved DVT only: $26 / 29(89.6 \%)$ \\
\hline Distal DVT only & $38(11.5)$ & \\
\hline Proximal \& distal DVT & $0(0)$ & \\
\hline Asymptomatic PE & $11(3.3)$ & \\
\hline Symptomatic PE & $0(0)$ & \\
\hline DVT \& PE combined & $24(7.3)$ & Total resolved DVT \& PE combined: 18/19 (94.7\%) \\
\hline Proximal DVT only & $3(0.9)$ & \\
\hline Distal DVT only & $20(6.1)$ & \\
\hline Proximal DVT & $6(1.8)$ & Total resolved proximal DVT: 4/4 (100\%) \\
\hline Symptomatic DVT & $8(2.4)$ & Total resolved symptomatic DVT: 8/8 (100\%) \\
\hline
\end{tabular}

Values are presented as number (\%).

DVT: deep vein thrombosis, PE: pulmonary embolism. 
TKA patients (906 $\mathrm{mL}$ in group $\mathrm{A}, \mathrm{p}=0.972 ; 1,021 \mathrm{~mL}$ in group $\mathrm{X} 7, \mathrm{p}=0.937$; and $1,058 \mathrm{~mL}$ in group $\mathrm{X} 10, \mathrm{p}=0.920$ ). In addition, in the cases that were excluded from the comparison because the MDCT was performed before 10 days postoperatively, no VTE event was noted.

\section{Discussion}

In the present study, we noted that rivaroxaban was more effective in lowering the incidence of VTE than AA and that the 10-day course of rivaroxaban was more effective than the 7-day course. Specifically, compared with AA, the absolute risk reduction for VTE, DVT, and PE with 7-day rivaroxaban was $18.2 \%$, $20 \%$ and $9.1 \%$, respectively; the absolute risk reduction for VTE, DVT, and PE with 10-day rivaroxaban was 26.8\%, 29.1\%, and $16.4 \%$, respectively. Although the 7 -day rivaroxaban regimen resulted in reduction in the incidence of VTE and DVT events, there was no significant difference in the PE incidence compared with the AA therapy. However, the 10-day rivaroxaban regimen significantly reduced the incidence of PE as well as VTE and DVT. Furthermore, no cases of proximal or symptomatic DVT were noted following prophylaxis with a 10-day regimen of rivaroxaban. Compared with the 7-day rivaroxaban regimen, the absolute risk reduction for VTE and PE with 10-day rivaroxaban was $10 \%$ and $7.3 \%$, respectively. Thus, the 10 -day rivaroxaban regimen yielded a significantly superior reduction compared with the 7-day rivaroxaban regimen in the incidence of PE plus proximal DVT plus symptomatic DVT, the three clinically important events.

At present, no definite strategy for thromboprophylaxis has been established in view of the American Academy of Orthopaedic Surgeons or the American College of Chest Physicians $(\mathrm{ACCP})^{15,16)}$. In the present study, the prophylactic regimens were determined by considering several factors. First, the average body weight of Korean patients (60 kg in this study) is lower than that of Caucasians $(79 \mathrm{~kg})^{17)}$. Second, all patients received concomitant mechanical prophylaxis. Third, Asians have certain genetic factors that are associated with a lower prevalence of thrombi ${ }^{6}$. Fourth, we considered some evidence that shows a favorable symptomatic VTE incidence without chemoprophylaxis in Asians ${ }^{2)}$. Thus, the prophylactic duration in the present study was set at 10 days, which is the minimal duration recommended by the ACCP ${ }^{16)}$, and the shorter duration of 7 days was set based on the fact that VTE most frequently occurs 5 to 7 days postoperatively $^{18)}$. The recommended rivaroxaban dose, $10 \mathrm{mg}^{12)}$, was the lowest dose available in tablet form. The comparative group received LMWH plus AA instead of no prophylaxis due to the ethical concern of withholding prophylaxis from patients. LMWH was initially used to enhance the prophylactic effect considering the increased VTE risk during the immediate postoperative period based on Virchow's triad (including venous stasis, endothelial injury, and hypercoagulability) and due to the nature of the procedure and/or the high flexion position during $\mathrm{TKA}^{18)}$. Therefore, we used a regimen involving 2 days of LMWH and 5 days of AA, which has shown satisfactory results in terms of the reduction in symptomatic VTE incidence ${ }^{19)}$. This is one of limitations of this study: we used $100 \mathrm{mg}$ due to the easy availability of the tablet form and the lower body mass of Korean patients.

The ACCP has recently approved the use of AA as a prophylactic treatment ${ }^{16)}$, and $100 \mathrm{mg}$ of AA has shown favorable effects with regard to reduction in the incidence of symptomatic $\mathrm{VTE}^{19)}$. However, in this study, AA did not seem to be effective: the incidences of VTE, PE, proximal DVT, and symptomatic DVT with AA were similar to those of another study without prophylaxis in Korean patients $\left(35.7 \%, 13.5 \%, 8.7 \%\right.$, and $3.2 \%$, respectively) ${ }^{20)}$.

In terms of asymptomatic distal DVT, 24/27 (88.8\%) of the cases with asymptomatic distal DVT showed complete resolution, and the remaining 3 cases showed significant improvements, with no complications. Moreover, patients who did not undergo followup MDCT had no suspicious DVT symptoms. Thus, in cases of asymptomatic distal DVT, observation without any specific treatment may be sufficient.

The need for thromboprophylaxis after TKA in Asians is still debatable. It is important to note that VTE should be considered as a "preventable disease". Surgeons should be aware that more than $90 \%$ of PEs develop as a result of lower extremity thrombi ${ }^{21)}$, asymptomatic DVT can cause the post-thrombotic syndrome, and $\mathrm{PE}$ can cause chronic thromboembolic pulmonary hyperten$\operatorname{sion}^{22}$. Moreover, surgeons have legal and ethical concerns over what can be considered "preventable". Although current guidelines focus on symptomatic events ${ }^{23)}$, symptomatic VTE cannot be selectively prevented.

The present study had several potential strengths. First, this was the first report of VTE incidence after TKA in Korean patients on the recommended or shorter duration of prophylactic therapy. Second, this study assessed VTE events via MDCT that is considered the best modality for detecting PE and $\mathrm{DVT}^{24)}$.

However, this study has several limitations. First, the preoperative VTE status could not be monitored. However, chronic VTE can be detected on MDCT performed to evaluate the formation of thrombi ${ }^{25)}$, and no chronic case of VTE was observed. Second, MDCT was performed at 10 days postoperatively; thus, we could 
not confirm whether VTE occurred afterwards. However, none of the patients showed any symptoms or signs of VTE during follow-up at 4-6 weeks and 3 months postoperatively in the outpatient department. Third, there was concern regarding radiation exposure with MDCT scans; however, the estimated radiation dose did not exceed the diagnostic reference level of radiation ${ }^{26)}$. Fourth, the incidence of VTE was evaluated only among different chemoprophylaxis regimens. However, to determine the need for chemoprophylaxis, the incidence of VTE following mechanical prophylaxis should be evaluated and compared to that following chemoprophylaxis. A well-designed comparative study of chemoprophylaxis and placebo is needed to establish guidelines for the Asian patients with TKA. Lastly, the inclusion of patients with staged bilateral TKA performed within 2 weeks might have affected the outcomes although only patients without VTE by MDCT at the 1st stage TKA were included.

\section{Conclusions}

Rivaroxaban had a lower incidence of overall VTE than AA, but no difference was observed in symptomatic VTE. The 10-day course of rivaroxaban had a lower incidence of overall VTE than the 7-day course.

\section{Conflict of Interest}

No potential conflict of interest relevant to this article was reported.

\section{References}

1. Geerts WH, Bergqvist D, Pineo GF, Heit JA, Samama CM, Lassen MR, Colwell CW. Prevention of venous thromboembolism: American College of Chest Physicians EvidenceBased Clinical Practice Guidelines (8th Edition). Chest. 2008;133(6 Suppl):381S-453S.

2. Lee WS, Kim KI, Lee HJ, Kyung HS, Seo SS. The incidence of pulmonary embolism and deep vein thrombosis after knee arthroplasty in Asians remains low: a meta-analysis. Clin Orthop Relat Res. 2013;471:1523-32.

3. Piovella F, Wang CJ, Lu H, Lee K, Lee LH, Lee WC, Turpie AG, Gallus AS, Planes A, Passera R, Rouillon A; AIDA investigators. Deep-vein thrombosis rates after major orthopedic surgery in Asia. An epidemiological study based on postoperative screening with centrally adjudicated bilateral venography. J Thromb Haemost. 2005;3:2664-70.
4. Leizorovicz A; SMART Venography Study Steering Committee. Epidemiology of post-operative venous thromboembolism in Asian patients: results of the SMART venography study. Haematologica. 2007;92:1194-200.

5. Russell RD, Hotchkiss WR, Knight JR, Huo MH. The efficacy and safety of rivaroxaban for venous thromboembolism prophylaxis after total hip and total knee arthroplasty. Thrombosis. 2013;2013:762310.

6. White RH, Keenan CR. Effects of race and ethnicity on the incidence of venous thromboembolism. Thromb Res. 2009; 123 Suppl 4:S11-7.

7. Ryu JH, Olson EJ, Pellikka PA. Clinical recognition of pulmonary embolism: problem of unrecognized and asymptomatic cases. Mayo Clin Proc. 1998;73:873-9.

8. Wang CJ, Wang JW, Weng LH, Hsu CC, Lo CF. Outcome of calf deep-vein thrombosis after total knee arthroplasty. J Bone Joint Surg Br. 2003;85:841-4.

9. Jaffe TA, Yoshizumi TT, Toncheva G, Anderson-Evans C, Lowry C, Miller CM, Nelson RC, Ravin CE. Radiation dose for body CT protocols: variability of scanners at one institution. AJR Am J Roentgenol. 2009;193:1141-7.

10. Saltybaeva N, Jafari ME, Hupfer M, Kalender WA. Estimates of effective dose for CT scans of the lower extremities. Radiology. 2014;273:153-9.

11. Colwell CW Jr, Berkowitz SD, Lieberman JR, Comp PC, Ginsberg JS, Paiement G, McElhattan J, Roth AW, Francis CW; EXULT B Study Group. Oral direct thrombin inhibitor ximelagatran compared with warfarin for the prevention of venous thromboembolism after total knee arthroplasty. J Bone Joint Surg Am. 2005;87:2169-77.

12. Turpie AG, Lassen MR, Davidson BL, Bauer KA, Gent M, Kwong LM, Cushner FD, Lotke PA, Berkowitz SD, Bandel TJ, Benson A, Misselwitz F, Fisher WD; RECORD4 Investigators. Rivaroxaban versus enoxaparin for thromboprophylaxis after total knee arthroplasty (RECORD4): a randomised trial. Lancet. 2009;373:1673-80.

13. Westrich GH, Haas SB, Mosca P, Peterson M. Meta-analysis of thromboembolic prophylaxis after total knee arthroplasty. J Bone Joint Surg Br. 2000;82:795-800.

14. Eriksson BI, Borris L, Dahl OE, Haas S, Huisman MV, Kakkar AK, Misselwitz F, Kalebo P; ODIXa-HIP Study Investigators. Oral, direct Factor Xa inhibition with BAY 59-7939 for the prevention of venous thromboembolism after total hip replacement. J Thromb Haemost. 2006;4:121-8.

15. Jacobs JJ, Mont MA, Bozic KJ, Della Valle CJ, Goodman SB, Lewis CG, Yates AC Jr, Boggio LN, Watters WC 3rd, Turkel- 
son CM, Wies JL, Sluka P, Hitchcock K. American Academy of Orthopaedic Surgeons clinical practice guideline on: preventing venous thromboembolic disease in patients undergoing elective hip and knee arthroplasty. J Bone Joint Surg Am. 2012;94:746-7.

16. Falck-Ytter Y, Francis CW, Johanson NA, Curley C, Dahl OE, Schulman S, Ortel TL, Pauker SG, Colwell CW Jr. Prevention of VTE in orthopedic surgery patients: Antithrombotic Therapy and Prevention of Thrombosis, 9th ed: American College of Chest Physicians Evidence-Based Clinical Practice Guidelines. Chest. 2012;141(2 Suppl):e278S-325S.

17. Turpie AG, Bauer KA, Eriksson BI, Lassen MR; PENTATHALON 2000 Study Steering Committee. Postoperative fondaparinux versus postoperative enoxaparin for prevention of venous thromboembolism after elective hip-replacement surgery: a randomised double-blind trial. Lancet. 2002; 359:1721-6.

18. Lieberman JR, Hsu WK. Prevention of venous thromboembolic disease after total hip and knee arthroplasty. J Bone Joint Surg Am. 2005;87:2097-112.

19. Lee JK, Chung KS, Baek SW, Choi CH. The prophylaxis of venous thromboembolism in Korean patients with total knee replacement arthroplasty. J Korean Orthop Assoc. 2012;47:86-95.

20. Park KH, Cheon SH, Lee JH, Kyung HS. Incidence of ve- nous thromboembolism using 64 channel multidetector row computed tomography-indirect venography and anticoagulation therapy after total knee arthroplasty in Korea. Knee Surg Relat Res. 2012;24:19-24.

21. Byrne JJ, O’neil EE. Fatal pulmonary emboli; a study of 130 autopsy proven fatal emboli. Am J Surg. 1952;83:47-9.

22. Kahn SR. The post-thrombotic syndrome: the forgotten morbidity of deep venous thrombosis. J Thromb Thrombolysis. 2006;21:41-8.

23. Barrack RL. Current guidelines for total joint VTE prophylaxis: dawn of a new day. J Bone Joint Surg Br. 2012;94(11 Suppl A):3-7.

24. Winer-Muram HT, Rydberg J, Johnson MS, Tarver RD, Williams MD, Shah H, Namyslowski J, Conces D, Jennings SG, Ying J, Trerotola SO, Kopecky KK. Suspected acute pulmonary embolism: evaluation with multi-detector row CT versus digital subtraction pulmonary arteriography. Radiology. 2004;233:806-15.

25. Park EA, Lee W, Lee MW, Choi SI, Jae HJ, Chung JW, Park JH. Chronic-stage deep vein thrombosis of the lower extremities: indirect CT venographic findings. J Comput Assist Tomogr. 2007;31:649-56.

26. Mettler FA Jr, Huda W, Yoshizumi TT, Mahesh M. Effective doses in radiology and diagnostic nuclear medicine: a catalog. Radiology. 2008;248:254-63. 